University of Wollongong

Research Online

Faculty of Social Sciences - Papers (Archive) Faculty of Arts, Social Sciences \& Humanities

2013

Clinical and reliable change in an Australian residential substance use program using the addiction severity index

Frank P. Deane

University of Wollongong, fdeane@uow.edu.au

Peter J. Kelly

University of Wollongong, pkelly@uow.edu.au

Trevor P. Crowe

University of Wollongong, tcrowe@uow.edu.au

Justin C. Coulson

University of Wollongong, jcoulson@uow.edu.au

Geoffrey C.B Lyons

University of Wollongong, glyons@uow.edu.au

Follow this and additional works at: https://ro.uow.edu.au/sspapers

Part of the Education Commons, and the Social and Behavioral Sciences Commons

Research Online is the open access institutional repository for the University of Wollongong. For further information contact the UOW Library: research-pubs@uow.edu.au 


\title{
Clinical and reliable change in an Australian residential substance use program using the addiction severity index
}

\author{
Abstract \\ Although the Addiction Severity Index (ASI) is one of the most frequently used measures in alcohol and \\ other drug research, it has rarely been used to assess clinical and reliable change. This study assessed \\ clients' clinical and reliable change at The Salvation Army residential substance abuse treatment centers \\ in Australia. A total of 296 clients completed ASI interviews on admission to treatment and 3 months \\ after discharge from treatment. Clients demonstrated significant improvement on all seven ASI \\ composites. The range of reliable change for each ASI composite varied from $30 \%$ to $70 \%$. More than \\ two-thirds of clients experienced clinically significant improvement for alcohol and drug problems. \\ Psychiatric distress was clinically reduced in $44 \%$ of clients. This research indicates that residential \\ substance abuse treatment can make important differences in client's lives at a clinical and functional \\ level. However, the research highlights the challenge of effectively targeting psychiatric comorbidity \\ within alcohol and other drug abuse populations.

\section{Keywords} \\ reliable, change, australian, clinical, residential, index, substance, program, addiction, severity \\ Disciplines \\ Education | Social and Behavioral Sciences

\section{Publication Details} \\ Deane, F. P., Kelly, P. J., Crowe, T. P., Coulson, J. C. \& Lyons, G. C.B. (2013). Clinical and reliable change in \\ an Australian residential substance use program using the addiction severity index. Journal of Addictive \\ Diseases, 32 (2), 194-205.
}


Running head: CLINICAL AND RELIABLE ASI CHANGE

Clinical and Reliable Change in an Australian Residential Substance Use Program Using the Addiction Severity Index

Frank P. Deane (PhD)

Peter J. Kelly (PhD), Trevor P. Crowe, (PhD), and Justin C. Coulson (PhD)

Illawarra Institute for Mental Health, School of Psychology, University of Wollongong.

Work carried out at the Illawarra Institute for Mental Health, School of Psychology, University of Wollongong.

Author for correspondence:

Author for correspondence: Frank P. Deane, Illawarra Institute for Mental Health, University of Wollongong, Wollongong, NSW, Australia, 2500. Telephone: 024221 4523, Email: fdeane@uow.edu.au 


\begin{abstract}
Although the Addiction Severity Index (ASI) is one of the most frequently used measures in alcohol and other drug (AOD) research, it has rarely been used to assess clinical and reliable change. This study assessed clients' clinical and reliable change at The Salvation Army residential substance abuse treatment centres, Australia. 296 clients completed ASI interviews upon admission to treatment and three months after discharge from treatment. Clients demonstrated significant improvement on all seven ASI composites. The range of reliable change for each ASI composite varied from 30\%-70\%. Over two thirds of clients experienced clinically significant improvement for alcohol and drug problems. Psychiatric distress was clinically reduced in $44 \%$ of clients. This research indicates that residential substance abuse treatment can make important differences in client's lives at a clinical and functional level. However, the research highlights the challenge of effectively targeting psychiatric co-morbidity within AOD abuse populations.
\end{abstract}


Clinical and Reliable Change in an Australian Residential Substance Use Program Using the Addiction Severity Index

Longitudinal research that measures change in substance abuse populations is relatively common. Such research provides evidence that interventions aimed at reducing and eliminating substance abuse and improving functioning in various life domains are making significant change in groups of people with alcohol and other drug (AOD) addictions, at least from a statistical perspective (Slaymaker \& Owen, 2006; Watkins, et al., 2011).

While such research is important, it does not reveal whether the magnitude of change is clinically meaningful (Burgess, Pirkis, \& Coombs, 2009). Specifically, a comparison of means from pre-intervention to post-intervention usually only reflects group differences and statistical change. With sufficient numbers of participants small but consistent changes may be statistically significant but offer less in terms of changes in an individual's overall experience of illness or recovery. That is, there may not be any functional change in the individual's lifestyle. A group of people abusing alcohol or other drugs may reduce their substance use significantly compared to a control group (or their prior use), yet the treatment group may still be experiencing substance abuse habits and issues consistent with those still meeting the criteria for a substance use disorder diagnosis. Thus a change in group means tells us little about the meaningfulness of that change, and also fails to discriminate between those individuals who are changing or who are not changing within the group (Bowersox, Saunders, \& Wojcik, 2009). Jacobson and Truax (1991) also indicated that analysis of group means typically provides a less conservative suggestion of intervention effectiveness that fails to consider actual improvement when contrasted with group mean differences. In short, tests of statistical significance provide information at the group level but indicate nothing about the number of individuals who have made clinical and reliable improvement in the 
assessed domain (Hiller, Schindler, \& Lambert, 2012; Jacobson \& Truax, 1991), a critical consideration when reviewing outcome measures after treatment (Burgess et al., 2009).

\section{Clinical and Reliable change}

Clinical and reliable improvement goes beyond a simple comparison of group means, and instead determines the efficacy of an intervention in moving a person from being classified as experiencing problems in a given area to being considered within a 'normal' population on that variable after following treatment (Bowersox et al., 2009; Jacobson \& Truax, 1991; Speer \& Greenbaum, 1995; Westbrook \& Kirk, 2005). It also shows that such change is reliably beyond any error in measurement (Bowersox et al., 2009; Hiller et al., 2012; Ogles, Lambert, \& Masters, 1996). The purpose of this paper is to explore the extent to which clinical and reliable change is demonstrated in clients receiving residential services provided by The Salvation Army in Australia for alcohol and other drug addictions. The Addiction Severity Index (ASI) was used as the central measurement tool for this study.

Research that is conducted to test for clinical and reliable change assesses change at the level of the individual, and allows advantages over standard tests of group means. These advantages might include organisational benchmarking (Billingham, et al., in press) and summaries of the percentage of clients who improve, deteriorate, or make no clinical improvements. This information can be useful within an organisation to assess treatment efficacy, but also to assess performance of individual units within an organisation, or to compare treatment efficacy with other organisations who publish data on their own performance (Kelly, 2010).

There are multiple methods for computing clinical and reliable change, although the Jacobson-Truax method is the most commonly used and accepted method (Jacobson \& Truax, 1991; Lopez-Goni, et al., 2010; Speer \& Greenbaum, 1995, 2002). Jacobson and 
Truax (1991) suggest three methods for calculating clinical change. The first (criterion a) requires clients who score in a clinical range on a specific variable of interest at baseline to move two standard deviations away from the clinical mean at follow up. Criterion $b$ requires clients to fall within two standard deviations of the 'normal' population mean at follow up. Criterion $c$ is the most stringent of Jacobson and Truax's (1991) alternatives, and requires that clients move so as to be closer to the normal population mean than the (baseline) clinical mean at follow up.

The value of assessing clinical and reliable change has been asserted consistently over the past decade (Billingham et al., in press; Bowersox et al., 2009), although there is still limited use of these types of analyses in the majority of studies conducted assessing substance abuse treatment efficacy. Only a small percentage of studies consider such change based on clinical and reliable change (Billingham et al., in press; Burgess et al., 2009; Hiller et al., 2012). By using clinical and reliable change as a standard by which to assess change, organisations can benchmark their treatment effectiveness, and track progress over time.

\section{The Addiction Severity Index and reliable change}

The Addiction Severity Index (ASI) is one of the world's most widely used and researched assessments of functioning in AOD clients (McLellan, Cacciola, Alterman, Rikoon, \& Carise, 2006). The measure consists of structured interview questions assessing client functioning across seven domains (e.g., drug, alcohol, psychiatric). While the ASI is widely used, we found no longitudinal analyses of residential AOD treatment clients that assessed clinical and reliable change on ASI composite scores, though some have used the reliable change index alone (Bodin \& Romelsjo, 2007; Lopez-Goni et al., 2010).

Lopez-Goni et al. (2010) investigated change in 112 drug abusers who remained in a Spanish inpatient community for the duration of a 12-month rehabilitation program and 
assessed the extent to which reliable change was demonstrated by the participants. There was substantial variation in the extent to which clients experienced reliable change in the various ASI domains, with change ranging from $7.9 \%$ of participants (in the family/social domain) to $66.7 \%$ of participants (in the alcohol consumption domain). Across all variables, a total of less than $10 \%$ of participants demonstrated reliable deterioration after treatment.

Similar results were obtained by Bodin and Romelsjo (2007), who used the RCI to demonstrate reductions in problem severity across five of the seven ASI domains. Of the 188 alcohol abusers in the study, $70.7 \%$ of clients who indicated alcohol problem severity in a range that would allow for reliable improvement were found to make such improvement. Only $13.8 \%$ of those who could reliably improve their drug problem severity scores who did so. Further reliable improvements were obtained in areas of secondary concern including family (11.2\%), psychiatric (18.6\%), and legal (12.2\%) problem severity. No significant improvement was found for medical and employment domains for these participants.

Research was also conducted by Currie et al. (2003) who used the ASI to analyse substance abusers experiencing chronic pain. They found highly statistically significant differences in mean alcohol scores from admission to follow up. Such comparison of group means, however, does not indicate the proportion of participants who improve, do not change, or who deteriorate. When using the RCI to demonstrate change, this statistical improvement equated to only between one quarter to one third of participants improving in various domains. To our knowledge, no studies have extended analysis from reliable change to clinically significant change for AOD treatment centre research.

The present study

We have found no previous longitudinal Australian research that has utilised the ASI for residential substance abuse clients. Moreover, there is a lack of research that assesses clinical 
and reliable change in Australian samples of substance abusers more generally, using any measures. The present study reports the characteristics of residential substance abuse treatment-seeking clients based on ASI data and provides a comparison with normative data from the United States. The study will examine the effectiveness of The Salvation Army substance abuse residential recovery programs on an intention-to-treat basis, and analyse client outcomes in terms of their statistical significance, but also using the clinical and reliable change as a central metric of improvement, stability, or deterioration. This research advances our understanding of the clinical efficacy of such interventions in each of the seven domains assessed by the ASI.

\section{Method}

\section{Participants}

From November 2008 until April 2011, the ASI was administered to 1105 participants within 14 days of admission to a residential drug and alcohol treatment service operated by The Salvation Army. This process took place across eight individual service locations in New South Wales, Queensland, and the Australian Capital Territory. Participants provided informed consent before participating in this study and all protocols received review and approval of the University of Wollongong Human Research Ethics Committee. Males comprised 83.1\% $(n=918)$ of the admission sample. Participants’ ages at admission ranged from 17 years to 73 years $(M=35.53, S D=10.61)$.

Follow-up data was collected from 296 of the original participants three months after leaving The Salvation Army Recovery Service. To be eligible for follow-up participation, clients must have completed an ASI within two weeks of admission to treatment, and must also have been a) available, b) willing to participate, and c) not have returned to treatment. The follow-up sample included 244 males (82.4\%). Participants average age was 37.09 years 
$(S D=10.99)$. Anglo-Australians were the dominant ethnic group (80.1\%), and Aboriginal Australians (6.1\%), English (3.4\%) and New Zealand participants (2.7\%) were the other major cultural groups represented in the sample. Average length of time in treatment was 107 days $(S D=93.15)$.

Those who chose to participate in the follow up ASI interview were no different at admission to those who did not participate in terms of age and ASI composite scores, except on the legal composite and the alcohol composite. Those who provided data at follow up had a significantly higher average alcohol composite score at admission $(M=.44, S D=.29)$ compared to those who did not participate in the follow up interview $(M=.39, S D=.30)$, $t(1159)=-2.26, p=02$. Conversely, those who provided data at follow up had significantly lower legal composite score $(M=.16, S D=.23)$ than those who did not participate in the follow up interview $(M=.23, S D=.24), t(1159)=-2.26, p=02$. Chi-square analysis revealed no significant differences in gender distribution, culture/ethnicity, or primary drug of choice when comparing participants who provided data at admission only with participants who participated at the 3-month follow up.

\section{Measures}

The Addiction Severity Index (ASI), version 5 (McLellan, et al., 1992), was administered to all participants within fourteen days of their admission to one of the agency's participating residential centres. The ASI is one of the most widely utilised substance abuse assessment tools in the world (Bodin \& Romelsjo, 2007; McLellan et al., 2006; McLellan, Kushner, Metzger, Peters, \& et al., 1992). It is a semi-structured interview that explores seven domains of functioning: medical history and status, employment, alcohol and other drug use and history, legal issues, family and social relationships, and psychiatric history and status. The ASI is used to obtain information from participants about their involvement in each of 
these domains for the past 30 days. In each domain the 30-day data is combined via a formula (see McGahan, Griffith, Parente, \& McLellan, 1986) to produce a non-standardised composite score (CS) ranging from .00 to 1.00. Higher scores indicate higher levels of dysfunction within the relevant domain.

The ASI has good internal consistency, test-retest reliability, and satisfactory validity (Alterman, Brown, Zaballero, \& McKay, 1994; Stoffelmayr, Mavis, \& Kasim, 1994). However there is some variability in findings regarding the ASI's psychometric properties, with more positive outcomes reported by the tool’s creators (McLellan, Kushner, Metzger, Peters, Smith et al., 1992) compared to others seeking to replicate their work (McCusker, Bigelow, Servigon, \& Zorn, 1994; Stoffelmayr et al., 1994). Nonetheless, research by Stöffelmayr et al. (1994) indicates that composite scores (which are particularly relevant for this study) show good longitudinal stability.

Procedure

A member of the research team (PK) trained The Salvation Army staff in ASI delivery utilising the Addiction Severity Index Module of the United Nations Drug Dependence Treatment Training Package (UNODC, n.d.). Training incorporated one day of direct instruction, group discussion, and role-plays. It was followed up with a booster session approximately 6-months after initial training. The Salvation Army incorporated the use of the ASI into routine operating procedures at each of the recovery service centres. Case managers were instructed to complete the ASI during the person's first seven days of residential care. As a result of work demands, on some occasions there were delays in the interview being completed. Consequently the present analysis allows a timeframe of up to two weeks for ASI interviews to have been completed. All data were entered into The Salvation Army Management Information System (SAMIS) and downloaded for analysis in PASW v19. 
Follow up interviews were conducted by trainer research assistants via telephone and occurred three months after participants had left residential care, whether they successfully completed treatment or not (i.e., intention to treat).

Analysis

ASI composite scores were the variables of interest in this study. Statistical change was measured using t-tests, comparing ASI composite scores at admission and 3 month follow up. Based on the recommendation of Speer and Greenbaum $(1995,2002)$ and more recent analysis from Lopez-Goni et al. (2010) the RCI calculations were based on the formula derived from Jacobson and Truax (1991). This formula is as follows:

$\mathrm{RCI}=\left(\mathrm{X}_{2}-\mathrm{X}_{1}\right) /\left(2\left[S D\left(1-\mathrm{r}_{\mathrm{xx}}\right)^{1 / 2}\right]^{2}\right)^{1 / 2}$ where $\mathrm{X}_{1}$ and $\mathrm{X}_{2}$ represent the admission and 3 month follow up scores respectively, $S D$ is the standard deviation of admission ASI data, and $r_{x x}$ is the test-retest reliability coefficient for the relevant ASI composite. The smaller the standard deviation of outcome scores and the higher the reliability of the instrument, the smaller the change that is required from admission to follow up to demonstrate reliable change in the individual. Reliable change is more difficult to demonstrate when measurement error increases and the associated variance in outcome data increases. Scores greater than or less than 1.96 (i.e., the 95\% range) indicate reliable change in either the positive or negative direction (Hiller et al., 2012; Lambert \& Ogles, 2009). Thus a person can be said to have changed reliably from admission to follow up by analysing a function of the measure's standard deviation and reliability, in this case its test-retest reliability.

Test-retest scores for this analysis were based on research by McCusker et al. (1994), who provided the following six composite test-retest correlation coefficients: alcohol $=.84$, drugs $=.85$, psychiatric $=.52$, employment $=.83$, legal $=.83$, and medical $=.51$. Because McCusker et al. did not provide a correlation for the family/social composite (due to protocol 
errors) the coefficient, $r=.63$, provided by Bodin and Romelsjo (2007) and Daeppen et al. (1996) was utilised in this analysis. McCusker et al.’s (1994) data was chosen because the sample incorporated drug abusers whereas Daeppen et al. (1996) and Bodin and Romelsjo (2007) focused on alcohol abusers alone. Moreover, as the test-retest reliability in McCusker et al.’s (1994) data is lower (i.e., higher measurement error), the analysis is more stringent because reliable improvement needs to be greater in order to exceed that larger error allowance (Bodin \& Romelsjo, 2007).

Clinically significant change was measured according to the most stringent criterion advocated by Jacobson and Truax (1991); criterion c. Only clients who were measured as closer to the clinical mean for a given variable at admission to treatment were included in this analysis, which was conducted using the formula:

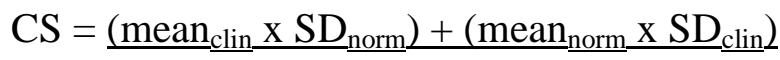

$$
\begin{aligned}
& \left(\mathrm{SD}_{\text {norm }}+\mathrm{SD}_{\text {clin }}\right)
\end{aligned}
$$

In this instance, the mean ${ }_{\text {clin }}$ and $\mathrm{SD}_{\text {clin }}$ is the mean and standard deviation for the clinical population (the current study) at admission, and the mean ${ }_{\text {norm }}$ and $\mathrm{SD}_{\text {norm }}$ is the mean and standard deviation for the non-clinical population. Normative data was taken from Weisner et al. (2000). Such data was available for four of the seven ASI composite scores (drug, alcohol, psychiatric, and medical).

Bowersox et al. (2009) indicated that some participants providing data as part of a clinical sample may not score in the clinical range. Moreover, some participants' scores may preclude them from making significant or reliable change. Therefore, as indicated previously, analyses have been conducted using only those participants who scored within the clinical range on each composite score during their initial ASI interview upon admission to treatment. 


\section{Results}

At admission, interviewers coded participants’ primary presenting addictions as follows: alcohol (54.8\%), amphetamines/stimulants (15\%), cannabis (13.6\%), and heroin (8.2\%). All other substances were reported as primary problems at rates of $1.6 \%$ or less. In the 30 days prior to admission, alcohol was the drug most likely to be consumed, followed by cannabis. Over three quarters of the sample had been previously treated for substance use or abuse. Smoking tobacco in the 30 days prior to admission was reported by $68.8 \%$ of clients. Mean number of cigarettes smoked per day was $12.83(S D=11.82)$. Approximately $80 \%$ of those admitted for treatment indicated either a history of depression or anxiety. More than half of the sample reported experiencing serious depression in the 30 days prior to admission, and $70 \%$ reported having experienced serious anxiety or tension in the same timeframe (see Table 1).

\section{$<<<$ INSERT TABLE 1 ABOUT HERE $>>>$}

Table 2 provides an overview of demographic characteristics of the sample at admission and at follow up, along with data for comparison from a sample of inpatients receiving AOD treatment in the United States from McLellan et al. (2006). This comparison reveals that the present sample reported greater problem severity across all seven ASI domains in contrast to the USA sample. This was particularly noticeable in the psychiatric domain, where the present sample reported much higher rates of lifetime experience of depression, anxiety, and suicide attempts.

$<<<$ INSERT TABLE 2 ABOUT HERE $>>>$

Group change from admission to follow up 
A series of t-tests on composite scores demonstrated significant differences across all seven ASI domains, indicating statistically significant improvement for clients between admission and three months follow-up. T-scores were as follows: Alcohol, $t(277)=13.39$, $p<.001$; Drug, $t(173)=9.64, p<.001$; Psychiatric, $t(274)=7.93, p<.001$; Employment, $t(328)=11.46, p<.001$; Medical, $t(275)=6.38, p<.001$; Family/Social, $t(265)=6.54$, $p<.001$; and Legal, $t(278)=6.39, p<.001$.

\section{Reliable change}

Table 3 provides cutoff scores and reliable change indices for each of the ASI composite scores.

\section{$<<<$ INSERT TABLE 3 ABOUT HERE $>>>$}

Table 4 illustrates that in the domains for which treatment was primarily being sought, reliable change was achieved for clients with alcohol problems in two-thirds of cases. For clients with other drug problems $70 \%$ showed a reliable change in scores in a positive direction. The five other domains assessed by the ASI showed varying proportions of reliable improvement for individual participants with the psychiatric composite offering the lowest rate of improvement. A small minority deteriorated in the alcohol and drug domains following treatment (see Table 4).

$<<$ INSERT TABLE 4 ABOUT HERE $>>>$

\section{Clinical and reliable change}

The percentage of clients who achieved a reliable and clinically significant change is shown in Table 5. Of the total sample, change ranged from $31.5 \%$ to $47.9 \%$. When only considering clients who presented with symptoms in the clinical range at baseline, the 
percentages of those who experienced clinically significant and reliable change increased markedly, as did the range of change achieved (43.9\% - 70.3\%).

$<<$ INSERT TABLE 5 ABOUT HERE $>>>$

\section{Correlation between ASI composite scores}

Table 6 provides the correlations between composite scores for each of the ASI domains at admission (below the diagonal) and follow up (above the diagonal). At admission the correlations were generally low, with few exceptions. A strong positive correlation was found between psychiatric and family composites, indicating that as psychiatric difficulties increased, so too did family problems. The same pattern was also shown between alcohol use, drug use, and psychiatric problems. All other correlations remained low in magnitude, although there were still many significant associations between composite scores. At follow up there were fewer significant correlations. Relationships between high alcohol and drug composites and high psychiatric composite scores were highly significant. A significant relationship was also found between alcohol and family composite scores. The psychiatric composite scores were significantly positively related to all six other ASI domains.

$<<$ INSERT TABLE 6 ABOUT HERE $>>>$

\section{Discussion}

The purpose of this study was to examine ASI data from clients in The Salvation Army residential substance abuse treatment programme in comparison to previously published ASI data of other AOD treatment recipients from the USA. It also aimed to determine rates of change using statistical, as well as clinically significant and reliable change indices. 
An international normative sample was described by McLellan et al. (2006) and provided data allowing comparisons with the Australian residential treatment sample. The present sample was higher than the comparison sample on all ASI composite scores indicating greater levels of distress and dysfunction in all seven areas assessed by the ASI when compared with a large overseas sample. Alcohol and other drug use composites were generally similar, though still higher in the present sample than in the McLellan et al. data.

Reliable change for individual scores from admission to 3 month follow up

When considering reliable change at an individual level, results indicate individual variability in response to treatment. Depending on the ASI composite of interest, up to $70 \%$ of symptomatic clients demonstrated improvement at follow up relative to their admission scores. The two best performing domains for reliable change were alcohol and drugs, which is understandable given the fact that clients were seeking treatment for difficulties in these areas. These outcomes suggest that two thirds of clients being admitted to The Salvation Army treatment programme experienced reductions in addiction by the three-month postdischarge follow up. However, around 34\% of clients did not demonstrate reliable improvement on the alcohol composite, and 30\% did not improve on the drug composite, despite having scores at admission indicating that improvement toward a more positive degree of functioning was possible. Only a small percentage of those we were able to follow up with (3\% and $2 \%$ respectively for alcohol and drugs) were found to have reliably deteriorated following discharge from the programme.

Using reliable change as the benchmark for improvement is a far more conservative approach to assess improvement in substance abuse treatment. The Reliable Change Index indicated that $36.5 \%$ of clients experiencing reliable improvement in the family/social domain, and just under 30\% of clients reliably improved in the psychiatric domain. These 
results are important as they demonstrate the rates of meaningful change in individuals' lives; changes that are easily overlooked in traditional statistical approaches based on assessing mean changes over time. The data are also consistent with research that has identified that clients who attend substance abuse treatment do not all require improvement in all life domains (Bodin \& Romelsjo, 2007; Lopez-Goni et al., 2010), and that many are functional at 'normal' levels in spite of their addictions.

\section{Correlations of composite scores}

Consistent with previous research (Bodin \& Romelsjo, 2007) correlations of composite scores were generally low across domains. While many were significant, the magnitude of the correlations was small at admission with just two exceptions: psychiatric and alcohol composites $(r=.33)$, and psychiatric and family/social composites $(r=.47)$. At follow up the size and number of significant relationships between composites was reduced. Again the psychiatric composite was concerning, with significant positive associations with both drugs $(r=.37)$ and alcohol $(r=.39)$. The consistent significant relationship between psychiatric composite scores and other ASI domains also highlights the importance of addressing co morbidity in the sample.

These findings highlight the importance of the issue of psychiatric co-morbidity in the AOD population. At admission psychiatric problem severity showed significant positive associations with problems in four of the six additional ASI domains, including drug and alcohol composites. By follow up this had increased to significant positive associations with all six of the other composites and the magnitude of those relationships had increased for drug, alcohol, employment, and legal composites. The present study attests to the highly complex difficulties experienced by those attending treatment for AOD abuse. Their drug addictions appear to co-occur with employment problems, psychiatric difficulties, social and 
family issues, legal troubles, and poor physical health. This research highlights the degree to which these individuals are at risk, and the importance of ensuring that the treatment agencies are adequately and appropriately resourced to provide treatment, with particular need for increased emphasis on psychiatric co morbidity (Dawes, Sitharthan, Conigrave, Phung, \& Weltman, 2011; Dingle \& King, 2009; Lai \& Huang, 2009; Nielsen, et al., 2011).

\section{Limitations}

A limitation of the study is the short term follow up administration of the ASI. The interview occurred only three months post-discharge. It is possible that clients' behavioural changes may be sustained in the short term following intervention, but that over time, the changes may be harder to maintain. This is particularly so if there are ongoing issues with cravings (Gordon, et al., 2006; Witkiewitz \& Bowen, 2010), psychiatric difficulties such as depression or other mood disorders (Shaikh \& Ghosh, 2011; Suter, Strik, \& Moggi, 2011; Witkiewitz \& Bowen, 2010), or a social or physical environment that discourages maintenance of new behaviours (Shaikh \& Ghosh, 2011). Further follow up will be necessary to determine the maintenance of these outcomes, particularly in the primary focal area of substance abuse, but also in the secondary domains related to psychiatric, social, legal, medical, and employment. A further limitation of this study is that no control group is employed.

Lastly, we have low follow-up rates. Some clients were unavailable for follow-up. This may have been due to the transient nature of many clients of services, relapse issues, or incarceration. Thus, the improvements we have obtained may be from a group of clients who were better placed to maintain their lifestyle changes when compared with those we were unable to contact to obtain follow-up data. Further, some clients were interviewed but provided no ASI data due to 'time' issues. As such, clients were 'interviewed' for five 
minutes on as much as possible, but often not inclusive of the ASI. Follow ups were, therefore, higher, but just not for specific ASI data.

\section{Strengths}

There are several strengths of this study. First, the study is the only research in Australia that we are aware of that utilises the ASI in a longitudinal manner to assess clinical and reliable change in AOD treatment service provision. The ASI's utility in substance abuse treatment research is substantial (McLellan et al., 2006; McLellan, Kushner, Metzger, Peters, \& et al., 1992; Stoffelmayr et al., 1994; Weisner et al., 2000). The ASI is a leading measure of AOD addiction internationally and allows comparison across other treatment settings and within the broader literature (McLellan et al., 2006). In particular, the comprehensive nature of the ASI demonstrates the differing outcomes that clients are experiencing following substance abuse treatment in multiple life domains. This is particularly useful information due to differences in health systems between countries which may mean different disorder and severity profiles. These need to be taken into account when benchmarking or in funding models for services. By using the ASI as a standard measure, such issues can be overcome through allowing description of the severity and complexity of particular treatment samples to be demonstrated in a standardised manner at a global level.

Another important strength of this study relates to the limited use of clinical and reliable change to determine the proportion of clients who are achieving functional treatment outcomes provides valuable information for treatment service providers via the ASI. There is limited research that considers clinical and reliable change on ASI composite scores. Moreover, this research facilitates ongoing improvements in the work that The Salvation Army does in assessing and improving services for people seeking treatment for AOD addiction. Additionally, the use of this kind of analysis adds to the quality of arguments for 
funding for residential treatment services by demonstrating clear results associated with treatment interventions. Last, the research highlights the critical role that psychiatric difficulty plays in functioning in all other aspects of these clients' lives. 


\section{References}

Alterman, A. I., Brown, L. S., Zaballero, A., \& McKay, J. R. (1994). Interviewer severity ratings and composite scores of the ASI: A further look. Drug and Alcohol Dependence, 34, 201-209. doi: doi:10.1016/0376-8716(94)90157-0

Billingham, D. D., Kelly, P. J., Deane, F. P., Crowe, T. P., Buckingham, M. S., \& Craig, F. L. (in press). Clinically significant change to establish benchmarks in residential drug and alcohol treatment services. International Journal of Mental Health and Addictions.

Bodin, M. C., \& Romelsjo, A. (2007). Secondary outcomes: Group and individual change and relationships to drinking outcomes. Addiction Research and Theory, 15, 587-599. doi: 10.1080/16066350701433282

Bowersox, N. W., Saunders, S. M., \& Wojcik, J. V. (2009). An evaluation of the utility of statistical versus clinical significance in determining improvement in alcohol and other drug (AOD) treatment in correctional settings: Erratum. [Erratum/Correction]. Alcoholism Treatment Quarterly, 27, 236. doi: http://dx.doi.org/10.1080/07347320802591700

Burgess, P., Pirkis, J., \& Coombs, T. (2009). Modelling candidate effectiveness indicators for mental health services. Australian and New Zealand Journal of Psychiatry, 43, 531538.

Currie, S. R., Hodgins, D. C., Crabtree, A., Jacobi, J., \& Armstrong, S. (2003). Outcome From Integrated Pain Management Treatment for Recovering Substance Abusers. The Journal of Pain, 4, 91-100. doi: http://dx.doi.org/10.1054/jpai.2003.17

Daeppen, J.-B., Burnand, B., Schnyder, C., Bonjour, M., \& et al. (1996). Validation of the addiction severity index in French-speaking alcoholic patients. Journal of Studies on Alcohol, 57, 585-590. 
Dawes, G. M., Sitharthan, T., Conigrave, K. M., Phung, N., \& Weltman, M. (2011). Patients admitted for inpatient cannabis detoxification: Withdrawal symptoms and impacts of common comorbidities. Journal of Substance Use, 16, 392-405. doi: http://dx.doi.org/10.3109/14659891.2010.499491

Dingle, G. A., \& King, P. (2009). Prevalence and impact of co-occurring psychiatric disorders on outcomes from a private hospital drug and alcohol treatment program. Mental Health and Substance Use: dual diagnosis, 2, 13-23. doi: http://dx.doi.org/10.1080/17523280802593319

Gordon, S. M., Sterling, R., Siatkowski, C., Raively, K., Weinstein, S., \& Hill, P. C. (2006). Inpatient Desire to Drink as a Predictor of Relapse to Alcohol Use Following Treatment. The American Journal on Addictions, 15, 242-245. doi: http://dx.doi.org/10.1080/10550490600626556

Hiller, W., Schindler, A. C., \& Lambert, M. J. (2012). Defining response and remission in psychotherapy research: A comparison of the RCI and the method of percent improvement. Psychotherapy Research, 22, 1-11.

Jacobson, N. S., \& Truax, P. (1991). Clinical significance: A statistical approach to defining meaningful change in psychotherapy research. Journal of Consulting and Clinical Psychology, 1, 12-19. doi: doi:10.1037//0022-006X.59.1.12

Kelly, P. J. (2010). Calculating clinically significant change: Applications of the Clinical Global Impressions (CGI) Scale to evaluate client outcomes in private practice. Clinical Psychologist, 14, 107-111. doi: 10.1080/13284207.2010.512015

Lai, H. M. X., \& Huang, Q. R. (2009). Comorbidity of mental disorders and alcohol- and drug-use disorders: Analysis of New South Wales inpatient data. Drug and Alcohol Review, 28, 235-242. doi: http://dx.doi.org/10.1111/j.1465-3362.2008.00021.x 
Lambert, M. J., \& Ogles, B. M. (2009). Using clinical significance in psychotherapy research: The need for a common procedure and validity data. Psychotherapy Research, 19, 493-501.

Lopez-Goni, J. J., Fernandez-Montalvo, J., Menendez, J. C., Yudego, F., Garcia, A. R., \& Esarte, S. (2010). Group and individual change in the treatment of drug addictions: A follow-up study in therapeutic communities. The Spanish Journal of Psychology, 13, 906-913.

McCusker, J., Bigelow, C., Servigon, C., \& Zorn, M. (1994). Test-retest reliability of the Addiction Severity Index composite scores among clients in residential treatment. American Journal on Addictions, 3, 254-262. doi: doi:10.3109/10550499409117260

McGahan, P. L., Griffith, J. A., Parente, R., \& McLellan, A. (1986). Addiction Severity Index: Composite scores manual. Philadelphia: Treatment Research Institute.

McLellan, A., Cacciola, J. C., Alterman, A. I., Rikoon, S. H., \& Carise, D. (2006). The Addiction Severity Index at 25: Origins, Contributions and Transitions. The American Journal on Addictions, 15, 113-124. doi:

http://dx.doi.org/10.1080/10550490500528316

McLellan, A., Kushner, H., Metzger, D., Peters, R., \& et al. (1992). The fifth edition of the Addiction Severity Index. Journal of Substance Abuse Treatment, 9, 199-213. doi: http://dx.doi.org/10.1016/0740-5472\%2892\%2990062-S

McLellan, A., Kushner, H., Metzger, D., Peters, R., Smith, I., Grisson, G., et al. (1992). The fifth edition of the Addiction Severity Index. Journal of Substance Abuse Treatment, 9, 199-213. doi: http://dx.doi.org/10.1016/0740-5472\%2892\%2990062-S

Nielsen, S., Bruno, R., Lintzeris, N., Fischer, J., Carruthers, S., \& Stoove, M. (2011). Pharmaceutical opioid analgesic and heroin dependence: How do treatment-seeking 
clients differ in Australia? Drug and Alcohol Review, 30, 291-299. doi: http://dx.doi.org/10.1111/j.1465-3362.2011.00302.x

Ogles, B. M., Lambert, M. J., \& Masters, K. S. (1996). Assessing ouctome in clinical practice. Massachusetts: Allyn \& Bacon.

Shaikh, F. A., \& Ghosh, A. (2011). Effect of social support and self-efficacy on depression among recovering substance users. Journal of Psychosocial Research, 6, 211-219.

Slaymaker, V. J., \& Owen, P. L. (2006). Employed men and women substance abusers: Job troubles and treatment outcomes. Journal of Substance Abuse Treatment, 31, 347-354. doi: http://dx.doi.org/10.1016/j.jsat.2006.05.008

Speer, D. C., \& Greenbaum, P. E. (1995). Five methods for computing significant individual client change and improvement rates: Support for an individual growth curve approach. Journal of Consulting and Clinical Psychology, 63, 1044-1048. doi: http://dx.doi.org/10.1037/0022-006X.63.6.1044

Speer, D. C., \& Greenbaum, P. E. (2002). Five methods for computing significant individual client change and improvement rates: Support for and individual growth curve approach. Correction to Speer and Greenbaum (1995). [Erratum/Correction]. Journal of Consulting and Clinical Psychology, 70, 1239. doi: http://dx.doi.org/10.1037/0022006X.70.6.1239

Stoffelmayr, B. E., Mavis, B. E., \& Kasim, R. M. (1994). The longitudinal stability of the Addiction Severity Index. Journal of Substance Abuse Treatment, 11, 373-378. doi: doi:10.1016/0740-5472(94)90048-5

Suter, M., Strik, W., \& Moggi, F. (2011). Depressive symptoms as a predictor of alcohol relapse after residential treatment programs for alcohol use disorder. Journal of Substance Abuse Treatment, 41, 225-232. doi: http://dx.doi.org/10.1016/j.jsat.2011.03.005 
UNODC. (n.d.). Drug dependence treatment training package. Volume A: Screening, assessment, and treatment planning Retrieved access date here, 2007, from http://www.unodc.org/ddt-training/treatment/a.html

Watkins, K. E., Hunter, S. B., Hepner, K. A., Paddock, S. M., de la Cruz, E., Zhou, A. J., et al. (2011). An effectiveness trial of group cognitive behavioral therapy for patients with persistent depressive symptoms in substance abuse treatment. Archives of General Psychiatry, 68, 577-584. doi:

http://dx.doi.org/10.1001/archgenpsychiatry.2011.53

Weisner, C., McLellan, A., \& Hunkeler, E. M. (2000). Addiction Severity Index data from general membership and treatment samples of HMO members: One case of norming ASI. Journal of Substance Abuse Treatment, 19, 103-109. doi: http://dx.doi.org/10.1016/S0740-5472\%2899\%2900103-8

Westbrook, D., \& Kirk, J. (2005). The clinical effectiveness of cognitive behaviour therapy: Outcome for a large sample of adults treated in routine practice. Behaviour Research and Therapy, 43, 1243-1261. doi: http://dx.doi.org/10.1016/j.brat.2004.09.006

Witkiewitz, K., \& Bowen, S. (2010). Depression, craving, and substance use following a randomized trial of mindfulness-based relapse prevention. Journal of Consulting and Clinical Psychology, 78, 362-374. doi: http://dx.doi.org/10.1037/a0019172 
CLINICAL AND RELIABLE ASI CHANGE

Table 1

ASI Comparison Data: Summary Scores and Past 30-Day Data by Age, Gender, and Normative Sample at Admission and at Follow up

\begin{tabular}{|c|c|c|c|}
\hline & $\begin{array}{l}\text { Inpatient } \\
\text { McLellan et al. } 2006 \\
N=8,429\end{array}$ & $\begin{array}{l}\text { All * } \\
\text { (Baseline sample) }\end{array}$ & $\begin{array}{l}\text { All** } \\
\text { (3-month follow up) }\end{array}$ \\
\hline \multicolumn{4}{|l|}{ Substance use } \\
\hline Alcohol composite score & $.33(.27)$ & $.41(.30)$ & $.17(.26)$ \\
\hline Mean days of alcohol drinking & $8(10)$ & $8.45(9.27)$ & $4.74(8.36)$ \\
\hline Mean days of heavy drinking ${ }^{\dagger}$ & $5(9)$ & $7.66(9.04)$ & $3.13(7.21)$ \\
\hline Drug composite score & $.11(.14)$ & $.14(.13)$ & $.04(.09)$ \\
\hline Mean days of heroin use & $2(8)$ & $.87(3.63)$ & $.28(2.41)$ \\
\hline Mean days of cocaine use & $3(8)$ & $.28(1.74)$ & $.01(.08)$ \\
\hline Mean days of marijuana use & $2(6)$ & $5.05(8.57)$ & $2.5(7.13)$ \\
\hline Mean days of amphetamine use & & $1.66(4.62)$ & $.48(2.65)$ \\
\hline \multicolumn{4}{|l|}{ Personal health: medical } \\
\hline Medical composite score & $.16(.29)$ & $.30(.33)$ & $.12(.26)$ \\
\hline Mean days of medical problems & $4(9)$ & $6.32(10.52)$ & $3.19(7.83)$ \\
\hline \multicolumn{4}{|l|}{ Personal health: psychiatric } \\
\hline Psychiatric composite score & $.20(.24)$ & $.42(.24)$ & $.29(.25)$ \\
\hline \% Reporting depression & $31 \%$ & $55.3 \%$ & $43.2 \%$ \\
\hline \% Reporting anxiety & $35 \%$ & $69.6 \%$ & $54.1 \%$ \\
\hline Mean days of psychiatric problems & $8(12)$ & $12.89(12.71)$ & $10.54(11.32)$ \\
\hline \multicolumn{4}{|l|}{ Social functioning: employment } \\
\hline Employment composite score & $.65(.32)$ & $.77(.20)$ & $.70(.29)$ \\
\hline Mean days paid for working & $8(10)$ & $2.16(6.27)$ & $3.88(8.20)$ \\
\hline Mean days of employment problems & $8(12)$ & $10.03(13.70)$ & $4.70(12.72)$ \\
\hline \multicolumn{4}{|l|}{ Social functioning: family/social } \\
\hline Family composite score & $.15(.21)$ & $.30(.24)$ & $.18(.19)$ \\
\hline Mean days family conflicts & $3(8)$ & $3.10(7.39)$ & $3.19(7.89)$ \\
\hline Mean days social conflicts & $2(6)$ & $1.61(4.50)$ & $\mathrm{Na}$ \\
\hline \% Currently living with person with alcohol problem & $13 \%$ & $18.6 \%$ & $\mathrm{Na}$ \\
\hline \% Currently living with person using or abusing drugs & $7 \%$ & $15 \%$ & $\mathrm{Na}$ \\
\hline \multicolumn{4}{|l|}{ Social functioning: legal } \\
\hline Legal composite score & $.20(.22)$ & $.22(.24)$ & $.10(.21)$ \\
\hline$\%$ in controlled environment & $68 \%$ & $23 \%$ & $17.2 \%$ \\
\hline Mean days illegal activity & $1(5)$ & $1.39(4.06)$ & $.06(.47)$ \\
\hline Mean days incarcerated & $2(6)$ & $4.22(9.24)$ & .19 (1.99) \\
\hline
\end{tabular}

Note. All values are based upon the thirty days prior to the administration of the ASI. All values are means, with standard deviations in parentheses. ${ }^{*} N$ varies from 614 (drug use composite) - 1105 (mean days paid for working) $* * N$ varies from 292 - 296 at 3-month follow up. 
CLINICAL AND RELIABLE ASI CHANGE

Table 2

Demographic Characteristics and Lifetime ASI Data from a Normative Sample and the Current Study

\begin{tabular}{|c|c|c|c|}
\hline & $\begin{array}{l}\text { Inpatients } \\
\text { McLellan et al. } 2006 \\
N=8,429\end{array}$ & $\begin{array}{l}\text { All* } \\
\text { (Current sample at } \\
\text { baseline) } \\
N=1105\end{array}$ & $\begin{array}{l}\text { Follow up sample } \\
\text { (Lifetime or past } 3 \\
\text { years measures at } \\
\text { baseline) } \\
N=296\end{array}$ \\
\hline Age yrs $(S D)$ & $36(10)$ & $35.5(10.61)$ & $37.09(10.09)$ \\
\hline Gender \% Male & $61 \%$ & $83.1 \%$ & $83 \%$ \\
\hline \multicolumn{4}{|l|}{ Ethnicity } \\
\hline$\%$ White (USA) or Anglo Australian (Aus) & $48 \%$ & $73.6 \%$ & $80.9 \%$ \\
\hline \% Black or African American & $28 \%$ & & \\
\hline \% Aboriginal/Torres Strait Islander & & $9.3 \%$ & $6.1 \%$ \\
\hline \multicolumn{4}{|l|}{ Marital Status } \\
\hline$\%$ Never married & $48 \%$ & $66.3 \%$ & $62.8 \%$ \\
\hline$\%$ Married or living as married & $14 \%$ & $5.8 \%$ & $5.9 \%$ \\
\hline \% Separated or Divorced & $32 \%$ & $23 \%$ & $30.2 \%$ \\
\hline \% Satisfied with marital status & $63 \%$ & $57.4 \%$ & \\
\hline \multicolumn{4}{|l|}{ Years of education } \\
\hline$\%<12$ years & $36 \%$ & $31.3 \%$ & $31.2 \%$ \\
\hline \% High school Graduate & $47 \%$ & $56.8 \%$ & $56.8 \%$ \\
\hline \% Technical college/Trade/TAFE & $11 \%$ & $4.2 \%$ & $4.5 \%$ \\
\hline \% University graduate or higher & $5 \%$ & $6 \%$ & $7.5 \%$ \\
\hline \multicolumn{4}{|l|}{ Substance use } \\
\hline$\%$ Previous drug and/or alcohol treatment & & $77.2 \%$ & $79.8 \%$ \\
\hline$\%$ With past history of overdoses & $15 \%$ & $26.9 \%$ & \\
\hline \% Used heroin & $22 \%$ & $26.5 \%$ & $33.3 \%$ \\
\hline$\%$ Used cocaine & $61 \%$ & $59.3 \%$ & $35.3 \%$ \\
\hline \% Used amphetamines & $26 \%$ & $67.2 \%$ & $70.8 \%$ \\
\hline \multicolumn{4}{|l|}{ Personal health: medical } \\
\hline \% Reporting a chronic medical problem & $32 \%$ & $32.1 \%$ & $34.0 \%$ \\
\hline$\%$ Taking medications & $26 \%$ & $26.3 \%$ & $29.1 \%$ \\
\hline \multicolumn{4}{|l|}{ Personal health: psychiatric } \\
\hline$\%$ Previously treated & $26 \%$ & $47 \%$ & $82.8 \%$ \\
\hline \% Taking medications & $31 \%$ & $35.9 \%$ & $38.3 \%$ \\
\hline \% Lifetime history of depression & $63 \%$ & $79.3 \%^{\ddagger}$ & $82.4 \%$ \\
\hline \% Lifetime history of anxiety & $58 \%$ & $81.8 \%$ & $83.5 \%$ \\
\hline$\%$ Lifetime history of suicide attempts & $20 \%$ & $36.9 \%$ & $39.5 \%$ \\
\hline \multicolumn{4}{|l|}{ Social functioning: Employment } \\
\hline \% Who have worked full-time & $79 \%$ & $78.2 \%$ & $96 \%$ \\
\hline \multicolumn{4}{|l|}{ Employment pattern, past 3 years } \\
\hline$\%$ Working (full-time or part-time) & $72 \%$ & $28 \%$ & $58.7 \%$ \\
\hline \% Unemployed & $20 \%$ & $23.6 \%$ & $24.3 \%$ \\
\hline \multicolumn{4}{|l|}{ Social functioning: family/social } \\
\hline \multicolumn{4}{|l|}{ Living situation past three years } \\
\hline$\%$ With sexual partner & $34 \%$ & $28.1 \%$ & $12.5 \% * *$ \\
\hline$\%$ With family & $29 \%$ & $23.2 \%$ & $15.2 \% * *$ \\
\hline$\%$ With friends & $7 \%$ & $8.8 \%$ & $16.9 \% * *$ \\
\hline$\%$ Other living situation & $27 \%$ & $39.9 \%$ & $55.5 \% * *$ \\
\hline \% Satisfied with living situation & $54 \%$ & $48.1 \%$ & $48.5 \% * *$ \\
\hline \% Reporting physical abuse in lifetime & $48 \%$ & $62.4 \%$ & $63.7 \%$ \\
\hline \% Reporting sexual abuse in lifetime & $28 \%$ & $30.8 \%$ & $36.9 \%$ \\
\hline \multicolumn{4}{|l|}{ Social functioning: legal } \\
\hline$\%$ Convicted of crime & $62 \%$ & $62.3 \%$ & $59.3 \%$ \\
\hline \% Incarcerated in lifetime & $59 \%$ & $42 \%$ & $26.1 \%$ \\
\hline
\end{tabular}


Table 3

Cut-off Scores and Reliable Change Index for ASI Composite Scores

\begin{tabular}{|l|l|l|}
\hline ASI Composite & Cut-off $^{\mathrm{b}}$ & Reliable Change Index $^{\mathrm{c}}$ \\
\hline Alcohol & .165 & .33 \\
\hline Drugs & .034 & .14 \\
\hline Employment $^{\mathrm{a}}$ & - & .24 \\
\hline Family $^{\mathrm{a}}$ & - & .42 \\
\hline Medical & .261 & .74 \\
\hline Psychiatric $^{\mathrm{a}}$ & .144 & .46 \\
\hline Legal $^{\mathrm{a}}$ & - & .27 \\
\hline
\end{tabular}

Note. ${ }^{\mathrm{a}}$ Normed scores not available for calculating cut-off scores. ${ }^{\mathrm{b}}$ Cut-offs calculated using Jacobson and Truax (1991) criterion c. ${ }^{\mathrm{c}}$ Denotes the amount of movement required in scores from admission to follow up to be considered reliable change. 
Table 4

Composite Score Means (SD’s), Number of Participants, and Reliable Change Following Intervention.

\begin{tabular}{|c|c|c|c|c|c|c|c|}
\hline ASI-CS & \multicolumn{3}{|c|}{ Group Means (SD’s)* } & \multicolumn{4}{|c|}{ Percentage of Participants with Reliable Change } \\
\hline Alcohol $^{\mathrm{a}}$ & $\begin{array}{c}.41 \\
(.31)\end{array}$ & $\begin{array}{l}.17 \\
(.25)\end{array}$ & $\begin{array}{l}1005 \\
(278)\end{array}$ & $\begin{array}{c}66.1 \\
(n=109)\end{array}$ & $\begin{array}{c}3 \\
(n=5)\end{array}$ & $\begin{array}{c}30.9 \\
(n=51)\end{array}$ & 165 \\
\hline Drugs & $\begin{array}{l}.14 \\
(.13)\end{array}$ & $\begin{array}{l}.04 \\
(.08)\end{array}$ & $\begin{array}{c}614 \\
(174)\end{array}$ & $\begin{array}{c}70.0 \\
(n=60)\end{array}$ & $\begin{array}{c}2 \\
(n=2)\end{array}$ & $\begin{array}{c}28 \\
(n=24)\end{array}$ & 86 \\
\hline Family & $\begin{array}{l}.30 \\
(.24)\end{array}$ & $\begin{array}{l}.19 \\
(.19)\end{array}$ & $\begin{array}{c}940 \\
(266)\end{array}$ & $\begin{array}{c}36.5 \\
(n=27)\end{array}$ & 0 & $\begin{array}{c}63.5 \\
(n=47)\end{array}$ & 74 \\
\hline Medical & $\begin{array}{l}.30 \\
(.33)\end{array}$ & $\begin{array}{l}.13 \\
(.16)\end{array}$ & $\begin{array}{l}1006 \\
(276)\end{array}$ & $\begin{array}{c}65.6 \\
(n=21)\end{array}$ & 0 & $\begin{array}{c}34.4 \\
(n=11)\end{array}$ & 32 \\
\hline Legal $^{\text {a }}$ & $\begin{array}{c}.29 \\
(.29)\end{array}$ & $\begin{array}{c}.10 \\
(.21)\end{array}$ & $\begin{array}{c}989 \\
(279)\end{array}$ & $\begin{array}{c}64.6 \\
(n=53)\end{array}$ & 0 & $\begin{array}{c}35.4 \\
(n=29)\end{array}$ & 82 \\
\hline
\end{tabular}

Note. ${ }^{\text {a }}$ These data are based on modified composite scores due to follow up data not including all composite score questions. * All CS's differ significantly when $p<.001{ }^{\dagger}$ The total number of cases where data was provided and reliable improvement was possible. 
Table 5

Clinically Significant Change on ASI Composite Scores: Total Sample and Sample with Asymptomatic Clients Removed.

\begin{tabular}{|c|c|c|c|c|c|c|}
\hline \multirow[b]{2}{*}{$\begin{array}{l}\text { ASI } \\
\text { Composite }\end{array}$} & \multicolumn{3}{|c|}{ Total Sample } & \multicolumn{3}{|c|}{ Asymptomatic Clients Removed } \\
\hline & $\begin{array}{c}\text { Clinically } \\
\text { significant } \\
\text { improvement } \\
\end{array}$ & $\begin{array}{c}\text { Neither clinically } \\
\text { improved nor } \\
\text { deteriorated }\end{array}$ & $\begin{array}{c}\text { Clinically } \\
\text { significant } \\
\text { deterioration } \\
\end{array}$ & $\begin{array}{c}\text { Clinically } \\
\text { significant } \\
\text { improvement }\end{array}$ & $\begin{array}{c}\text { Neither clinically } \\
\text { improved nor } \\
\text { deteriorated }\end{array}$ & $\begin{array}{l}\text { Clinically } \\
\text { significant } \\
\text { deterioration }\end{array}$ \\
\hline Drug & $40.2 \%$ & $39.2 \%$ & $.6 \%$ & $67.1 \%$ & $32.9 \%$ & N/A \\
\hline Psychiatric & $31.5 \%$ & $66.33 \%$ & $2.17 \%$ & $43.9 \%$ & $56.1 \%$ & N/A \\
\hline
\end{tabular}


Table 6

Correlations of Composite Scores at Admission and Follow up 3 months After Leaving Residential Treatment

\begin{tabular}{|c|c|c|c|c|c|c|c|}
\hline & Alcohol & Drug & Psychiatric & Employment & Family & Legal & Medical \\
\hline Alcohol & & $.34 * *$ & $.39 * *$ & .09 & $.30 * *$ & .09 & .07 \\
\hline Drug & .00 & & $.37 * *$ & .10 & .11 & $.13^{*}$ & -.03 \\
\hline Psychiatric & $.33 * *$ & $.24 * *$ & & $.13^{*}$ & $.21 * *$ & $.13^{*}$ & $.18 * *$ \\
\hline Employment & $-.07 *$ & .02 & .00 & & .01 & .08 & .02 \\
\hline Family & $.24 * *$ & $.23 * *$ & $.47 * *$ & -.06 & & .06 & .08 \\
\hline Legal & $-.12 * *$ & $.10^{*}$ & -.02 & $-.09 * *$ & .05 & & -.02 \\
\hline Medical & $.15 * *$ & .00 & $.23 * *$ & $.09 * *$ & $.10 * *$ & -.03 & \\
\hline
\end{tabular}

Note. $N$ for Time 1 ranges from 825-937 on all variables except drug-related responses (ranging from 533-598). $N$ for follow up ranges from 294-296. * $p<.05 . * * p<.01$. Admission scores are below the diagonal and follow-up scores are above the diagonal. 